\title{
303 応力波の伝播と自由面との干渉
}

\section{A propagation of a stress wave and an interaction with a free surface}

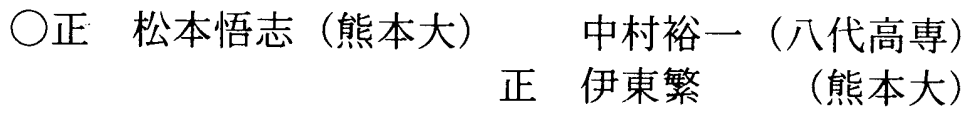
Satoshi MATSUMOTO and Shigeru ITOH, Shock Wave and Condensed Matter Research Center, Kumamoto University, 2-39-1, Kurokami, Kumamoto-shi, Kumamoto

Yuichi NAKAMURA, Yatsushiro National College of Technology, 2627, Hirayamashin-machi, Yatsushiro-shi, Kumamoto

\begin{abstract}
We make a new SPH (Smoothed Particle Hydrodynamics) code based on MLS (Moving Least Squares) method to analyze the dynamics of stress wave. The new code is examined by the simulation of an elastic wave interacted with a free surface. The result using the new code is compared with both the result of SPH and the experimental results of the model blasting using the electric detonator. The elastic wave emanates from the charge hole and interacts with the free surface. Propagation of elastic wave and reflection at the free surface are well simulated by the new method compared with SPH method.
\end{abstract}

Key Words: $\quad$ Smoothed Particle Hydrodynamics, Moving Least Squares, Elastic Wave, Free Surface, PMMA

\section{1. はじめに}

固体媒体中の応力波の伝播や固体境界での反射と透 過のような応力波の動的な挙動は，爆破に関する基本的 な研究問題である(1)。このような現象を明らかにするこ とは, 地下空洞開発やコンクリート構造物の爆破解体な どにおいて重要となる効率的な爆破工法の確立につなが る。数值シミュレーションは, 非常に瞬間的な現象であ る爆破過程中の応力波の動的挙動を調べるために有効で ある。数値解析法のほとんどは空間の離散化のためにメ ッシュを必要とするが，これは局所的に形状が大きくひ ずむ場合や複雑な形状を有する解析においては不利とな る。このようなことから、著者らは解析に格子を必要と しない粒子法の一つである SPH (Smoothed Particle Hydrodynamics）を用いて応力波の自由面との干渉やそ れによって生じる空気中の衝撃波について解析を行って きた(2) (3)。SPH は簡便な方法であるが，境界部の取り扱 いに工夫を要する場合が多い。このような久点を改善す る方法の一つとして移動最小自乗法 (Moving Least Squares）を取り入れた SPH 法が提案されている(4)。

本研究では MLS をべースとした SPH コードを作成 し, 自由面を有する PMMA 内部の二次元弾性波解析を 行い，その有効性を検討した。

\section{2. 数值解析法}

等方線形弾性体に対する基礎式は,

$$
\begin{aligned}
& \frac{D \rho}{D t}=-\rho \frac{\partial v_{k}}{\partial x_{k}} \\
& \frac{D v_{i}}{D t}=\frac{1}{\rho} \frac{\partial \sigma_{i k}}{\partial x_{k}} \\
& \frac{D \varepsilon_{i j}}{D t}=\frac{1}{2}\left(\frac{\partial v_{i}}{\partial x_{j}}+\frac{\partial v_{j}}{\partial x_{i}}\right)
\end{aligned}
$$

$$
\sigma_{i j}=\lambda \varepsilon_{k k} \delta_{i j}+2 \mu \varepsilon_{i j}
$$

である。ここで $\rho, \nu, \sigma, \varepsilon$ はそれぞれ密度, 速度, 応力お よびひずみを表し， $\lambda, \mu$ はラメの定数である。

これらの基礎式を SPH 法のカーネル近似を用いて定 式化すると, 以下の離散式が得られる。

$$
\begin{aligned}
& \frac{D \rho^{i}}{D t}=-\rho^{i} \sum_{j}\left(v_{k}^{j}-v_{k}^{i}\right) \frac{m^{j}}{\rho^{j}} \frac{\partial W}{\partial x_{k}} \\
& \frac{D v_{l}^{i}}{D t}=\frac{1}{\rho^{i}} \sum_{j}\left(\sigma_{l k}^{j}+\sigma_{l k}^{i}+\Pi \delta_{l k}\right) \frac{m^{j}}{\rho^{j}} \frac{\partial W}{\partial x_{k}} \\
& \frac{D \varepsilon_{l m}^{i}}{D t}=\frac{1}{2} \sum_{j} \frac{m^{j}}{\rho^{j}}\left[\left(v_{l}^{j}-v_{l}^{i}\right) \frac{\partial W}{\partial x_{m}}+\left(v_{m}^{j}-v_{m}^{i}\right) \frac{\partial W}{\partial x_{l}}\right]
\end{aligned}
$$

ここで上付添字 $i, j$ はある点の粒子およびその近傍の粒 子を意味する。また $m, W$ は，それぞれ粒子の質量および カーネル関数である。カーネル関数としては三次スプラ イン関数を用いた。Пは人工粘性項であり，以下を用い た。

$$
\Pi=\bar{\rho}^{i j}\left(\alpha \bar{c}^{i j}+\beta\left|\mu^{i j}\right|\right) \mu^{i j}, \mu^{i j}=\bar{h}^{i j} \frac{v_{k}^{i j} x_{k}^{i j}}{\left|r^{i j}\right|^{2}+\eta \bar{h}^{i j^{2}}}(8)
$$

ここで $f^{i j}=f^{i}-f^{j}, \vec{f}^{i j}=\left(f^{i}+f^{j}\right) / 2$ 。

MLS 法ではある点の物理量を $u^{h}(x)=p^{T}(x) a(x)$ と近 似する。 $J=\sum_{j} W\left(x-x_{j}\right)\left[u^{h}\left(x_{j}\right)-u_{j}\right]^{2}$ が最小となるよ うに $a(x)$ を決定すれば, 物理量の近似值は,

$$
u^{h}(x)=\sum p^{T}(x) A^{-1}(x) B(x) u_{j}=\sum \Phi_{j} u_{j}
$$




$$
\begin{aligned}
& A(x)=\sum_{j} W\left(x-x_{j}\right) p\left(x_{j}\right) p^{T}\left(x_{j}\right) \\
& B(x)=W\left(x-x_{j}\right) p\left(x_{j}\right)
\end{aligned}
$$

と形状関数 $\Phi$ を用いて表すことができる。 $p^{T}$ としては 一般に多項式が用いられ，本研究では一次基底 $p^{T}=[1, x, y]$ を用いた。式(5) (7)の SPH 法の離散式にお いて $W^{j} / \rho^{j} \rightarrow \Phi_{j}$ と置き換えることによって MLS-SPH の離散式を得ることができる。なお, 形状関 数の一階微分は,

$$
\frac{\partial \Phi_{j}}{\partial x}=\frac{\partial p^{T}}{\partial x} A^{-1} B+p^{T} \frac{\partial A^{-1}}{\partial x} B+p^{T} A^{-1} \frac{\partial B}{\partial x}
$$

より求めることができる。

\section{3. 解析条件}

図 1 は, 今回解析対象とした直角コーナー自由面を有 する PMMA の概略図である。これは従来の実験や解析 で用いたものと同様である(2) (3)。超音波パルス法で得ら れた供試体の密度, 音速, ヤング率およびポアソン比は それぞれ, $1188 \mathrm{~kg} / \mathrm{m}^{3}, 2.62 \mathrm{~km} / \mathrm{s}, 5.39 \mathrm{GPa}, 0.33$ である。 本研究では簡単のために平面ひずみ状態を仮定し, $x, y$ 各軸に対して対称とした。また外部の空気について は無視している。初期粒子は $1 \mathrm{~mm}$ 等間隔に配置し, チ ヤージホール部では放射状の速度分布を与え, 時間とと もに減少させた。境界粒子では応力を零とし，その他の 物理量は周りの粒子の值から定義式を用いて近似した。

\section{4. 結果と考察}

図 2,3 K MLS-SPH とSPH によって得られた密度分 布を示す。

図 2 に示すように, 自由面と干渉していない状態では 両者ともほほ同様の分布を示していることが分かる。し かしながら SPH の結果では, 境界部で大きな密度の低 下が見られる。このような密度の低下は, 状態方程式を 用いて圧力を決定する場合、特に影響が大きい。

図2のように, 自由面と干涉するまでは, 弾性波の進 行方向前方で圧縮, 後方で引張が生じるため, 密度は前 方で高く後方で低い。自由面との干涉で生じる反射波で は，これらが反対となる。図 3(a)に示す MLS-SPH の結 果では，このような現象を良くとらえていることがわか る。しかしながら SPH では境界部の影響によりかなり 異なる結果となった。図 4 は実験により得られたシャド ウグラフの一つである(2) (3)。この図では反射波が直角コ 一ナ一の二等分線上で干渉していることが確認できる。 MLS-SPH の結果を見ると同様の位置や右上部で反射波 同士の干渉による密度変化が見られる。現象が異なるた

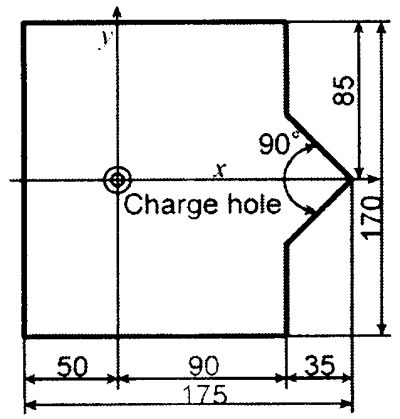

Fig. 1 Detail of PMMA specimen

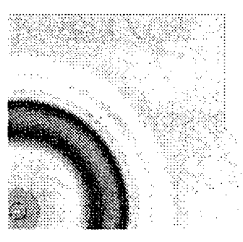

(a) MLS

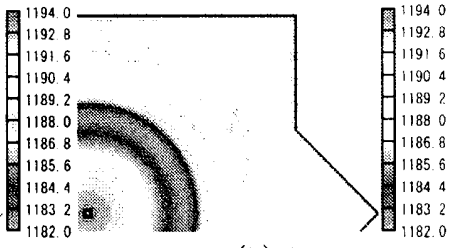

(b) $\mathrm{SPH}$
Fig. 2 Density distributions ( $\mathrm{t}=20 \mu \mathrm{s})$

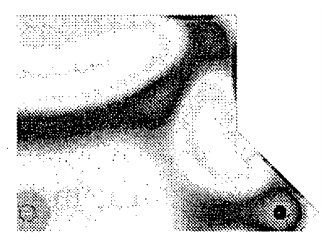

(a) MLS

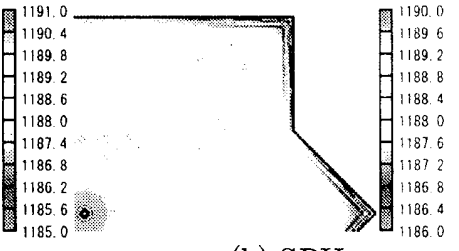

(b) $\mathrm{SPH}$

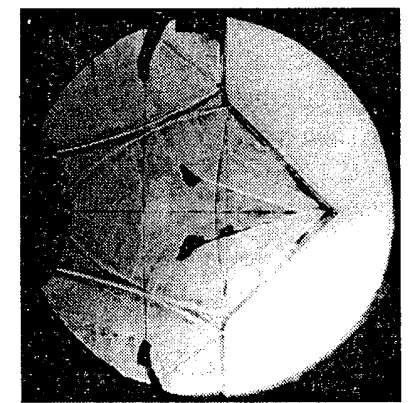

Fig. 4 Shadowgraph $(\mathrm{t}=52 \mu \mathrm{s})$

め, 直接比較することはできないものの, 応力波の反射 や干涉に対するMLS-SPHの有効性を示していると思わ れる。

\section{5. まとめ}

固体媒体中の応力波の伝播之自由面との干涉を解析 するために, MLS をべースとする SPH 法のコードを作 成し, 直角自由面を有する PMMA を対象として二次元 弾性波解析を行い以下の結果を得た。

（1）自由面と干涉する以前において MLS-SPH と通常 のSPH は同様の結果を示した。

(2) 通常の SPH 法では自由面で密度が減少し, 反射 波についても正しくとらえることができなかった。 MLS-SPH ではほほ問題ない結果が得られた。

(3) MLS-SPH で得られた結果は, 直角コーナーの二 等分線上や右上部で反射波の干涉を示し, 実験結果と類 似の傾向を示した。

\section{参考文献}

(1) W.L. Fourney, ほか 3 名, Fragmentation Mechanism in Crater Blasting, Int.J.Rock Mech.Min.Sci. \& Geomech.Abstr. Vol.30 (1993), No.4, 413.

(2) Satoshi MATSUMOTO, 他 2 名, Dynamic behavior of Stress Waves in Blasting Process, Material Sci. Forum Vols. 465-466, 2004, pp.55-60.

(3) Satoshi MATSUMOTO, 他 2 名, Visualization and Numerical Analysis of Stress Waves in Blasting Process, J. of Visualization, 2003, Vol. 6, No. 3, pp.235-244.

(4) G.A. Dilts, Moving-Least-Squares-Particle Hydrodynamics - I. Consistency and Stability, Int. J. Numer. Meth. Engng., 1999, 44, pp.1115-1155. 